\title{
Sagittal bending of the optic nerve at the entrance from the intracranial to the optic canal and ipsilateral visual acuity in patients with sellar and suprasellar lesions
}

\author{
Rei Yamaguchi, MD, Masahiko Tosaka, MD, Takaaki Miyagishima, MD, Tadashi Osawa, MD, \\ Keishi Horiguchi, MD, Fumiaki Honda, MD, and Yuhei Yoshimoto, MD \\ Department of Neurosurgery, Gunma University Graduate School of Medicine, Maebashi, Gunma, Japan
}

OBJECTIVE Visual acuity impairment due to sellar and suprasellar tumors is not fully understood. The relationship between these tumors and disturbance of visual function was examined using preoperative MRI.

METHODS This study reviewed 93 consecutive patients with sellar and suprasellar tumors. Best-corrected visual acuity (BCVA) and visual impairment score (VIS) were used for estimation of visual impairments. Preoperative MR images were examined to obtain several values for estimation of chiasmatic compression. Additionally, the optic nerve-canal bending angle (ONCBA) was newly defined as the external angle formed by the optic nerve in the optic canal and the optic nerve in the intracranial subarachnoid space at the junction, using preoperative sagittal T2-weighted MR images.

RESULTS The mean ONCBA was about the same on the right $\left(44^{\circ} \pm 25^{\circ}\right)$ and the left $\left(44^{\circ} \pm 24^{\circ}\right)$. Sagittal ONCBA was defined as large $\left(>45^{\circ}\right)$ and moderate $\left(\leq 45^{\circ}\right)$ on each side. Preoperative VIS was found to be significantly worse if the right or left ONCBA (or both) was large (right side: ONCBA large [median 20, IQR 8-30] > ONCBA moderate [median 10, IQR 3-17], $p=0.003$, Mann-Whitney U-test; left side: ONCBA large [median 22, IQR 9-30] > ONCBA moderate [median 10, IQR 2-16], $p=0.001$ ). A large ONCBA showed a significant relationship with unfavorable ipsilateral BCVA ( $>\log M A R, 0$; right side, $p=0.001$, left side, $p=0.001$, chi-square test). The ONCBA had a positive correlation with ipsilateral BCVA (right: $r=0.297, p=0.031$; left: $r=0.451, p=0.000$, Pearson's correlation coefficient). Preoperative BCVA was significantly lower on the same side in the large ONCBA group compared with the moderate ONCBA group (right side: large ONCBA $0.169 \pm 0.333$ [logMAR, mean \pm standard deviation] vs moderate ONCBA $0.045 \pm 0.359, p=0.026$, Student t-test; left side: large ONCBA $0.245 \pm 0.346$ vs moderate ONCBA $0.025 \pm 0.333, p=0.000$ ). This visual acuity impairment improved after resection of the tumors.

CONCLUSIONS Sagittal bending of the optic nerve at the entrance from the intracranial subarachnoid space to the optic canal may be related to ipsilateral deterioration of visual acuity in sellar and suprasellar lesions. Sagittal T2-weighted $\mathrm{MRI}$ is recommended for preoperative estimation of the optic nerve bending.

https://thejns.org/doi/abs/10.3171/2019.9.JNS191365

KEYWORDS visual function; visual acuity; sellar and suprasellar lesions; MRI; pituitary surgery

$\mathrm{S}$ ELLAR and suprasellar tumors occur close to the optic apparatus and often manifest as visual disturbances, varying from visual field defects and decreased visual acuity to blindness. ${ }^{8,9,36,37}$ Visual disturbances associated with sellar and suprasellar lesions are believed to be the result of chiasmatic compression. . $^{2,8,9,11,23,33,34,36,37,44}$ Pituitary adenomas with suprasellar extension can com- press the crossing fibers in the optic chiasm and disturb the local blood supply, leading to uni- or bitemporal quadrantanopia or hemianopia. ${ }^{8,24}$ Suprasellar extension of the tumor extending for more than $12-13 \mathrm{~mm}$ on the coronal MR image, or $8 \mathrm{~mm}$ on the sagittal image, ${ }^{16,38}$ and tumor size are also related to visual field defect if the tumor height is $20-30 \mathrm{~mm}$ or more. ${ }^{1}$ Other sellar and suprasel-

ABBREVIATIONS BCVA = best-corrected visual acuity; FSE = fast spin-echo; IQR = interquartile range; ONCBA = optic nerve-canal bending angle; OR = odds ratio; VIS = visual impairment score.

SUBMITTED May 17, 2019. ACCEPTED September 16, 2019.

INCLUDE WHEN CITING Published online December 13, 2019; DOI: 10.3171/2019.9.JNS191365. 
lar tumors, including craniopharyngiomas, Rathke's cleft cysts, tuberculum sellae meningiomas, and chordomas, show some variations in the compression pattern to the optic chiasm. ${ }^{10,11,36}$ Even these tumors often cause uni- or bitemporal quadrantanopia or hemianopia due to compression of the crossing fibers of the optic chiasm. ${ }^{11,36,37}$ Surgical management decisions often depend principally on the extent of deterioration of the visual fields. ${ }^{25}$ However, severe unilateral vision loss sometimes occurs even with relatively small suprasellar extension. In this study we examine the relationship between preoperative visual disturbance and preoperative MRI findings in patients with sellar and suprasellar tumors.

\section{Methods}

This study was approved by the IRB of Gunma University Graduate School of Medicine. This study reviewed the clinical records of 184 consecutive patients with sellar and suprasellar tumors who underwent endoscopic transsphenoidal surgery, including the classic sellar approach and extended transtubercular transplanum approach, from April 2010 to August 2017 at Gunma University Hospital, a teaching and tertiary care hospital and a major referral site for patients with brain tumors. All endoscopic transsphenoidal surgeries were performed by the senior author (M.T.). Sixty patients with tumors not in contact with the optic nerve pathway, including microadenoma, were excluded, and some were included as visually normal controls as described below. We also excluded 25 cases in which identification of the optic nerve was difficult using preoperative MRI, 3 cases with unilateral blindness, and 3 cases in which data were not available. Ninety-three patients were ultimately included in this study, comprising 42 women and 51 men, with a mean age of $53.7 \pm 16.6$ years. A normal control series was needed to establish the radiologically measured value. Among the 60 patients with normal vision who were excluded, including those with microadenomas, 48 patients ( 33 women and 15 men, with a mean age of $52.9 \pm 15.5$ years) with an optic nerve completely unaffected on MRI were used as normal controls for investigation of the optic apparatus.

\section{Ophthalmological Evaluation}

Ophthalmological examination consisted of testing the patient's visual acuity with optimum correcting lenses and Goldmann perimetry for both eyes. Ophthalmological findings of visual acuity and visual fields were analyzed independently. The best-corrected visual acuity (BCVA) was recorded as Snellen acuity fraction and converted to $\log$ MAR notation. . $^{13,22}$ Goldmann perimetry was performed using white dots of different sizes and brightness. Postoperative BCVA was examined within 3 months after surgery.

The visual impairment score (VIS) according to the German Ophthalmological Society was calculated by adding the scores of the tables for assessing BCVA and the visual field defects; each table combined the findings for both eyes..$^{11,20,32}$ VIS shows the overall visual function as the sum of the scores of BCVA and visual field defects (ranging from 0 to 100). The scores of BCVA and visual field defects were determined using the table combining the left and right findings before summing (Fig. 1). ${ }^{11,32}$

\section{MRI}

MRI was performed with a 1.5- or 3-T system, imaging the sellar and suprasellar lesions in all patients. Coronal and sagittal T1-weighted fast spin-echo (FSE) MR images with or without gadolinium enhancement, and coronal T2weighted FSE images were obtained in all patients. The sequential parameters were previously reported. ${ }^{39}$ Section thickness was $3 \mathrm{~mm}$ and the intersection gap was $0 \mathrm{~mm}$. Sagittal T2-weighted FSE MRI of the pituitary adenoma was obtained in $89 \%$ of patients (TR $3500-4500 \mathrm{msec}$, TE $85-98 \mathrm{msec}$, flip angle $90^{\circ}-150^{\circ}$, section thickness 3 $\mathrm{mm}$, intersection gap $0 \mathrm{~mm}$, matrix $384 \times 224-307$, and field of view 180-220 mm).

Measurements on MRI in patients with sellar and suprasellar tumors were defined as follows. The maximum diameter on the craniocaudal axis was defined as tumor height (Fig. 2A). ${ }^{41}$ The tumor top-anterior skull base distance was obtained by measuring from the anterior skull base to the apex of the tumor perpendicular to the frontal cranial base (Fig. 2B).$^{28}$ Chiasm height was defined as the shortest distance between the line connecting the frontal skull base and the posterior clinoid process to the chiasm (Fig. 2C) ${ }^{27}$ The prefixed chiasm (located above the tuberculum sellae), the postfixed chiasm (situated superior to the dorsum sellae), and the remaining normal chiasm were defined as previously explained (Fig. 2D-F). ${ }^{36}$ The sagittal optic nerve-canal bending angle (ONCBA) was defined as follows. The external angle formed by the optic nerve in the optic canal and the optic nerve in the intracranial subarachnoid space was measured at the entrance of the optic canal. This external angle is common in the evaluation of the bending angle of various materials (Figs. $2 \mathrm{G}$ and 3). ${ }^{18}$ The optic nerve is fixed in the optic canal. ${ }^{26}$ The optic nerve sometimes bends three-dimensionally at the exit of the optic canal in patients with sellar and suprasellar tumors. The ONCBA is the angle obtained by measuring this bending on the sagittal MR images. The mean ONCBA was approximately $45^{\circ}$ on both the right $\left(44^{\circ} \pm 25^{\circ}\right)$ and the left $\left(44^{\circ} \pm 24^{\circ}\right)$. A large bending angle was defined as more than $45^{\circ}$ (Fig. $2 \mathrm{H}$ ) and a moderate bending angle was defined as $45^{\circ}$ or less (Fig. 2I). Two independent observers (R.Y. and T.M.) reviewed the conventional and sagittal T2-weighted MR images, and assessed these measurements. Both observers made initial evaluations independently, and consensus resolved any disagreements regarding the final measurement.

\section{Statistical Analysis}

Tumor height, tumor top-anterior skull base, chiasm height, and ONCBA were divided by the mean value, and compared using VISs (Table 1). The relationships between clinical and MRI variables and VIS were examined using the Mann-Whitney U-test or 1-way ANOVA (Table 1). The relationships between preoperative unfavorable BCVA on the left and right and selected MRI variables-including tumor height, tumor top-anterior skull base, chiasm height, and ONCBA - were examined using the chi-square 
Visuol acuity

\begin{tabular}{|l|l|l|l|l|l|l|l|l|l|l|l|l|l|l|l|}
\hline & 1,0 & 0,8 & 0,63 & 0,5 & 0,4 & 0,32 & 0,25 & 0,2 & 0,16 & 0,1 & 0,08 & 0,05 & 0,02 & 0 \\
\hline & $5 / 5$ & $5 / 6$ & $5 / 3$ & $5 / 10$ & $5 / 12$ & $5 / 15$ & $5 / 20$ & $5 / 25$ & $5 / 30$ & $5 / 50$ & $1 / 12$ & $1 / 20$ & $1 / 50$ & 0 \\
\hline 1,00 & $5 / 5$ & 0 & 2 & 4 & 6 & 8 & 10 & 12 & 15 & 17 & 20 & 22 & 25 & 27 & 30 \\
\hline 0,8 & $5 / 6$ & 2 & 4 & 8 & 10 & 12 & 15 & 17 & 20 & 22 & 25 & 27 & 30 & 32 & 35 \\
\hline 0,63 & $5 / 8$ & 4 & 8 & 15 & 17 & 20 & 22 & 25 & 27 & 30 & 32 & 35 & 37 & 10 & 12 \\
\hline 0,5 & $5 / 10$ & 6 & 10 & 17 & 20 & 22 & 25 & 27 & 30 & 32 & 35 & 40 & 12 & 15 & 17 \\
\hline 0,4 & $5 / 12$ & 8 & 12 & 20 & 22 & 25 & 30 & 32 & 35 & 37 & 40 & 42 & 17 & 50 & 52 \\
\hline 0,32 & $5 / 15$ & 10 & 15 & 22 & 25 & 30 & 35 & 40 & 45 & 47 & 50 & 55 & 57 & 60 & 62 \\
\hline 0,25 & $5 / 20$ & 12 & 17 & 25 & 27 & 32 & 40 & 50 & 52 & 55 & 5 & 60 & 65 & 67 & 70 \\
\hline 0,2 & $5 / 25$ & 15 & 20 & 27 & 30 & 35 & 45 & 52 & 55 & 57 & 60 & 65 & 70 & 75 & 80 \\
\hline 0,16 & $5 / 30$ & 17 & 22 & 30 & 32 & 37 & 47 & 55 & 57 & 60 & 65 & 70 & 75 & 80 & 85 \\
\hline 0,1 & $5 / 50$ & 20 & 25 & 32 & 35 & 40 & 50 & 57 & 60 & 65 & 75 & 80 & 85 & 87 & 90 \\
\hline 0,08 & $1 / 12$ & 22 & 27 & 35 & 40 & 12 & 55 & 60 & 65 & 70 & 80 & 85 & 50 & 92 & 95 \\
\hline 0,05 & $1 / 20$ & 25 & 30 & 37 & 42 & 17 & 57 & 65 & 70 & 75 & 85 & 90 & 98 & 100 & 100 \\
\hline 0,02 & $1 / 50$ & 28 & 32 & 40 & 45 & 50 & 60 & 67 & 75 & 80 & 87 & 92 & 100 & 100 & 100 \\
\hline 0 & 0 & 30 & 35 & 42 & 47 & 52 & 62 & 70 & 80 & 85 & 90 & 95 & 100 & 100 & 100 \\
\hline
\end{tabular}

Visuol field defect

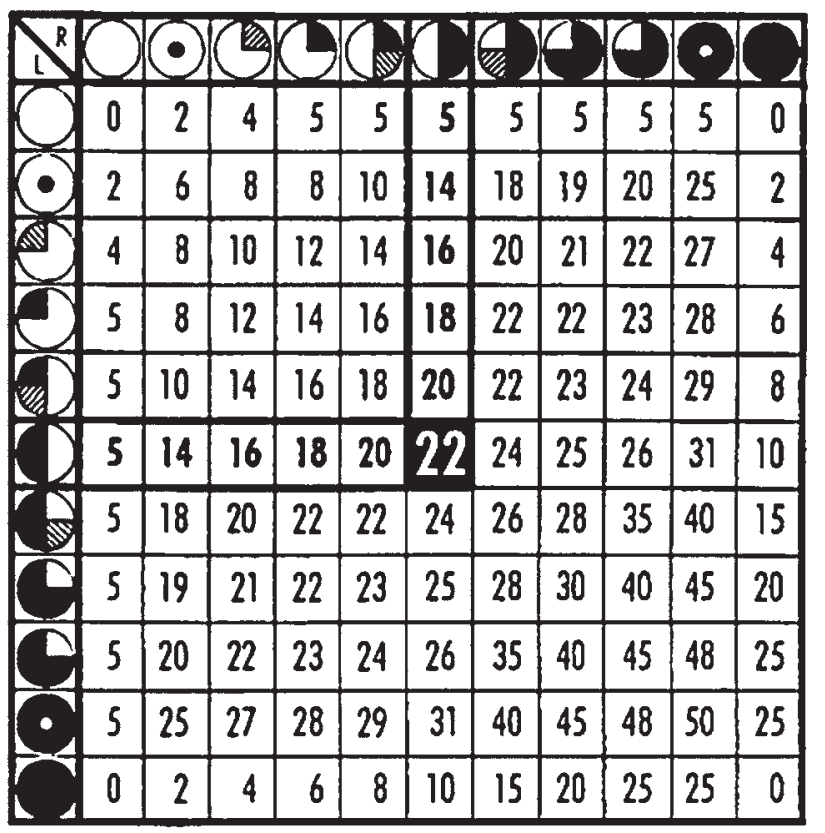

FIG. 1. Tables of visual acuity and visual field defect used for calculation of the VIS. The marked numbers provide an example of the calculation made in a patient with a visual acuity of 4/10 in the left eye and 2/10 in the right eye, together with a bitemporal visual field defect. The numbers 35 and 22, added together, total 57 . This number represents the VIS, which reaches 100 as a maximum. Reprinted with permission from Fahlbusch R, Schott W: Pterional surgery of meningiomas of the tuberculum sellae and planum sphenoidale: surgical results with special consideration of ophthalmological and endocrinological outcomes. J Neurosurg 96:235-243, 2002.

test (Table 2). The correlation between ONCBA and visual acuity was examined using $\log$ MAR vision on the left and the right with the Pearson correlation coefficient (Fig. 4). The difference between preoperative $\log$ MAR visual acuity on large and moderate sides was examined using the Student t-test. The difference between pre- and postoperative $\log$ MAR visual acuity was examined using the paired Student t-test (Fig. 5). A p value $<0.05$ was considered statistically significant. Statistical analyses were performed with SPSS for Mac OS (version 24.0, IBM Corp.).

\section{Results}

All tumors included suprasellar extension causing deviation of the optic nerve pathway, and visual dysfunction was recognized before surgery. Pituitary adenoma was found in 74 cases, and craniopharyngioma in 13 Rathke's cleft cysts in 6 cases. Eleven cases were recurrences, all nonfunctional pituitary adenomas. Good visual acuity with a BCVA of $\log$ MAR of 0 or less was found in 58 cases on the right and 50 cases on the left. Median VIS values (interquartile range [IQR]) of visual acuity, visual field defect, and the total were 4 (IQR 0-10), 8 (IQR 2-14), and 12 (IQR 6-25), respectively. The mean tumor height, tumor top-anterior skull base, and chiasm height were $27.0 \pm 6.7$ $\mathrm{mm}, 11.7 \pm 5.4 \mathrm{~mm}$, and $0.7 \pm 3.5 \mathrm{~mm}$, respectively. The chiasm position was prefixed, normal, or postfixed in 12 , 71 , and 10 cases, respectively. The mean ONCBA was approximately $45^{\circ}$ on the right $\left(44^{\circ} \pm 25^{\circ}\right)$ and left $\left(44^{\circ} \pm\right.$ $24^{\circ}$; Table 1). The mean ONCBA in the normal control group was approximately $5^{\circ}$ or $6^{\circ}$ on the left $\left(5.3^{\circ} \pm 4.8^{\circ}\right)$ and right $\left(6.3^{\circ} \pm 4.9^{\circ}\right)$, respectively.

\section{Visual Impairment Score}

Relationships were examined between clinical observations, imaging variables, and VISs (Table 1). The VIS field defect score tended to be higher in the group with a tumor top-anterior skull base of $12 \mathrm{~mm}$ or more compared to the other group $(p=0.007)$. The VIS total score was significantly higher in the large right ONCBA group (median 20, IQR 8-30) compared to the moderate right ONCBA group (median 10, IQR 3-17; p = 0.003, MannWhitney U-test). Similarly, VIS was significantly higher in the large left ONCBA group (median 22, IQR 9-30) compared to the moderate right ONCBA group (median 10 , IQR $2-16 ; p=0.001)$. Other clinical and imaging variables were not related to preoperative VIS (Table 1).

\section{Visual Acuity}

Investigation of the relationship between ONCBA and unilateral unfavorable visual acuity found that large ONCBA $\left(>45^{\circ}\right)$ showed a significant relationship to ipsilateral unfavorable BCVA ( $>\log \mathrm{MAR}, 0$; right side: odds ratio $[\mathrm{OR}] 4.405, \mathrm{p}=0.001$; left side: $\mathrm{OR} 3.968, \mathrm{p}=0.001$, chi-square test; Table 2). Tumor height, tumor top-anterior skull base, and chiasm height were not significantly related to preoperative BCVA (Table 2). ONCBA had a positive correlation with ipsilateral BCVA (right: $\mathrm{r}=$ $0.297, p=0.031$; left: $r=0.451, p=0.000$, Pearson's cor- 

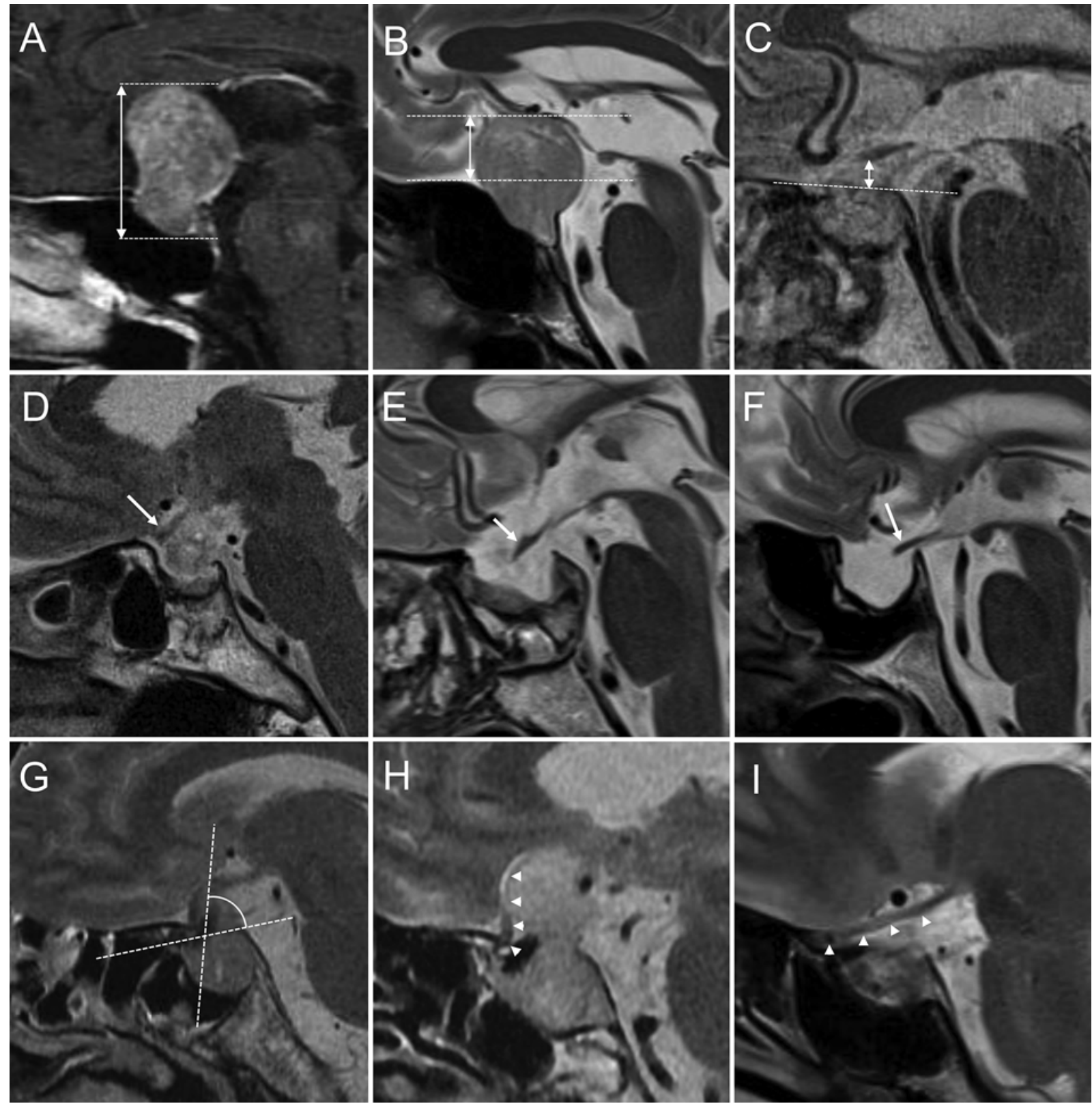

FIG. 2. Preoperative sagittal T1-weighted gadolinium-enhanced (A) and T2-weighted (B-I) MR images. A: Tumor height was defined as the maximum diameter in the craniocaudal axis. B: Tumor top-anterior skull base was obtained by measuring the distance from the anterior skull base to the apex of the tumor perpendicular to the frontal cranial base. C: Chiasm height was defined as the shortest distance between the line connecting the frontal skull base and the posterior clinoid process to the chiasm. D: Prefixed chiasm was located above the tuberculum sellae. The optic chiasm is indicated by the arrow. E: A normal chiasm was defined as excluding the prefixed and postfixed chiasm. F: A postfixed chiasm is situated superior to the dorsum sellae. G: The ONCBA was formed by the optic nerve in the optic canal and the optic nerve in the intracranial subarachnoid space at the exit of the optic canal (angle indicated by white dotted lines). H: A large ONCBA angle was $>45^{\circ}$. The optic chiasm and nerve path are indicated by arrowheads. The optic nerve is running at a right angle. I: A moderate ONCBA was $\leq 45^{\circ}$. The optic nerve is running almost in a straight line (arrowheads).

relation coefficient; Fig. 4). Visual acuity impairment may become severe as the ONCBA approaches a right angle. The preoperative BCVA was significantly lower on the same side in the large ONCBA group than in the moderate ONCBA group (right side: large ONCBA $0.169 \pm$ 0.333 [logMAR] vs moderate ONCBA $0.045 \pm 0.359, \mathrm{n}=$ 49 vs $44, p=0.026$, Student t-test; left side: large ONCBA
$0.245 \pm 0.346$ vs moderate ONCBA $0.025 \pm 0.333, \mathrm{n}=$ 44 vs 49, $p=0.000$; Fig. 5). Ipsilateral BCVA improved on the large ONCBA side after surgery, with significant differences on both sides (right side: before $0.169 \pm 0.333$ $[\log M A R]$ vs after $0.071 \pm 0.341, \mathrm{n}=49, \mathrm{p}=0.011$, Student t-test; left side: before $0.245 \pm 0.346$ vs after 0.083 $\pm 0.329, n=44, p=0.000 ;$ Fig. 5). In contrast, ipsilateral 


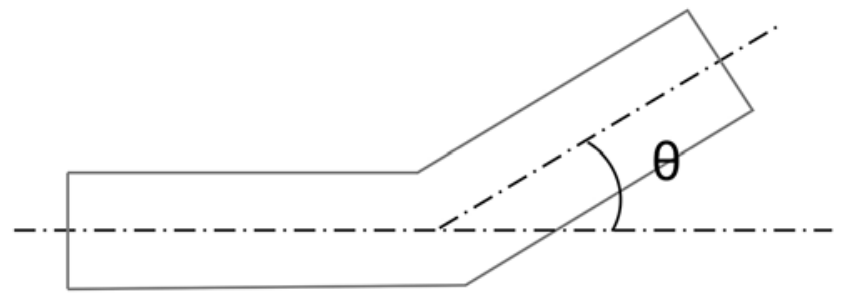

FIG. 3. Bending angle diagram. The ONCBA was defined as the external angle formed by the optic nerve in the optic canal and the optic nerve in the intracranial subarachnoid space at the entrance of the optic canal. $^{18}$

BCVA was good before surgery on the moderate ONCBA side, and no change occurred after surgery on both sides (right: large angle $0.071 \pm 0.341$ vs moderate angle $0.021 \pm$ $0.345, \mathrm{n}=44, \mathrm{p}=0.486$; left side: large angle $0.083 \pm 0.329$ vs moderate angle $0.007 \pm 0.272, n=49, p=0.226$; Fig. $5)$. We provide images from two representative cases for demonstration of the relationship between ONCBA and ipsilateral BCVA (Fig. 6).

\section{Discussion}

Visual acuity impairment due to sellar and suprasellar lesions has been believed to generally result from chiasmatic compression. ${ }^{8,9,17,23,33,34,36,37}$ Chiasmatic compression passes through stages, starting as a supratemporal defect, spread of the defect to the inferotemporal quadrant, followed by peripheral constriction, then loss of central vision with residual nasal field, and finally loss of all vision. ${ }^{8,13,33,34}$ Conventional clinical neurosurgical practice considers visual field disturbance, such as temporal hemianopia, as an essential neurological symptom to consider for the surgical indication of sellar and suprasellar lesions. The high frequency of visual acuity disturbance has been believed to be part of the phenotype originating from chiasmal compression. ${ }^{9,13,33}$ However, we sometimes see patients with very poor visual acuity on one side only (Fig. 6).

We first investigated the relationship between VIS and MRI variables. The degree of chiasmatic compression (tumor top-anterior skull base distance) affected only the visual field score of VIS, consistent with previous reports. Suprasellar extension of the tumor ${ }^{17,38}$ and tumor size are

TABLE 1. Relationship between clinical and MRI variables and the VIS

\begin{tabular}{|c|c|c|c|c|c|c|c|}
\hline \multirow[b]{2}{*}{ Variable } & \multirow{2}{*}{$\begin{array}{c}\text { No. of } \\
\text { Pts }\end{array}$} & \multicolumn{2}{|c|}{ Visual Acuity } & \multicolumn{2}{|c|}{ Visual Field Defect } & \multicolumn{2}{|l|}{ Total } \\
\hline & & Median (IQR) & p Value & Median (IQR) & $p$ Value & Median (IQR) & $\mathrm{p}$ Value \\
\hline Sex & & & 0.059 & & 0.780 & & 0.244 \\
\hline Male & 51 & $2(0-8)$ & & $6(2-14)$ & & $12(6-24)$ & \\
\hline Female & 42 & $5(0-18)$ & & $8(2-14)$ & & $16(8-26)$ & \\
\hline Tumor recurrence & & & 0.883 & & 0.429 & & 0.551 \\
\hline Yes & 11 & $2(0-20)$ & & $10(2-20)$ & & $18(2-38)$ & \\
\hline No & 82 & $4(0-10)$ & & $7(2-13)$ & & $12(6-24)$ & \\
\hline Tumor height, mm & & & 0.934 & & 0.096 & & 0.251 \\
\hline$\geq 27$ & 44 & $4(0-14)$ & & $8(6-20)$ & & $16(8-26)$ & \\
\hline$<27$ & 49 & $4(0-10)$ & & $6(2-11)$ & & $10(4-23)$ & \\
\hline Tumor top-anterior skull base, $\mathrm{mm}$ & & & 0.479 & & $0.007 \dagger$ & & $0.045^{*}$ \\
\hline$\geq 12$ & 39 & $4(0-15)$ & & $10(6-22)$ & & $18(8-26)$ & \\
\hline$<12$ & 54 & $2(0-9)$ & & $6(2-10)$ & & $10(2-23)$ & \\
\hline Chiasma height, mm & & & 0.147 & & 0.907 & & 0.536 \\
\hline$\geq 0.7$ & 40 & $4(0-15)$ & & $6(4-10)$ & & $12(6-24)$ & \\
\hline$<0.7$ & 53 & $2(0-9)$ & & $8(2-14)$ & & $12(2-26)$ & \\
\hline Chiasma position & & & 0.611 & & $0.014^{*}$ & & 0.252 \\
\hline Prefixed & 12 & $4(1-10)$ & & $15(7-24)$ & & $21(13-26)$ & \\
\hline Normal & 71 & $2(0-10)$ & & $6(2-10)$ & & $10(4-24)$ & \\
\hline Postfixed & 10 & $8(2-21)$ & & $7(4-16)$ & & $23(8-30)$ & \\
\hline Rt ONCBA & & & $0.007 \dagger$ & & $0.043^{*}$ & & $0.003 \dagger$ \\
\hline Large $\left(>45^{\circ}\right)$ & 49 & $6(0-19)$ & & $10(4-18)$ & & $20(8-30)$ & \\
\hline Moderate $\left(\leq 45^{\circ}\right)$ & 44 & $0(0-8)$ & & $6(2-10)$ & & $10(3-17)$ & \\
\hline Lt ONCBA & & & $0.006 \dagger$ & & $0.031^{*}$ & & $0.001 \dagger$ \\
\hline Large $\left(>45^{\circ}\right)$ & 44 & $8(1-17)$ & & $9(5-18)$ & & $22(9-30)$ & \\
\hline Moderate $\left(\leq 45^{\circ}\right)$ & 49 & $0(0-8)$ & & $6(2-11)$ & & $10(2-16)$ & \\
\hline
\end{tabular}


TABLE 2. Relationship between unilateral unfavorable BCVA and MRI variables

\begin{tabular}{|c|c|c|c|}
\hline Variable & OR & $95 \% \mathrm{Cl}$ & $p$ Value \\
\hline \multicolumn{4}{|l|}{ Rt side $(B C V A>\log M A R, 0)$} \\
\hline Tumor height ( $\geq 27$ mm) & 1.608 & $0.687-3.759$ & 0.273 \\
\hline $\begin{array}{l}\text { Tumor top-anterior skull base } \\
\qquad(\geq 12 \mathrm{~mm})\end{array}$ & 0.941 & $0.403-2.198$ & 0.889 \\
\hline Chiasma height ( $\geq 0.7 \mathrm{~mm})$ & 0.838 & $0.360-1.953$ & 0.682 \\
\hline \multicolumn{4}{|l|}{ Large ONCBA $\left(>45^{\circ}\right)$} \\
\hline Rt & 4.405 & $1.748-11.111$ & $0.001^{*}$ \\
\hline $\mathrm{Lt}$ & 0.903 & $0.389-2.092$ & 0.811 \\
\hline \multicolumn{4}{|l|}{ Lt side $(B C V A>\log M A R, 0)$} \\
\hline Tumor height ( $\geq 27$ mm) & 0.750 & $0.331-1.721$ & 0.490 \\
\hline $\begin{array}{l}\text { Tumor top-anterior skull base } \\
(\geq 12 \mathrm{~mm})\end{array}$ & 0.705 & $0.308-1.613$ & 0.407 \\
\hline Chiasma height ( $\geq 0.7 \mathrm{~mm})$ & 0.537 & $0.234-1.233$ & 0.141 \\
\hline \multicolumn{4}{|l|}{ Large ONCBA $\left(>45^{\circ}\right)$} \\
\hline Rt & 1.503 & $0.623-3.425$ & 0.329 \\
\hline $\mathrm{Lt}$ & 3.968 & $1.672-9.433$ & $0.001^{*}$ \\
\hline
\end{tabular}

also related to visual field defect. ${ }^{1}$ We found that severe sagittal bending of the optic nerve at the left or right exit of the optic canal greatly affects the VIS, or total visual function. The influence of the visual acuity score might be an important factor in the increase in VIS in patients with sellar and suprasellar lesions (Table 1). VIS was calculated from the numerical values of visual acuity and field using a special formula combining left and right sides, and summing the values of visual acuity and field. ${ }^{11}$ Therefore, VIS does not show the individual function of the left and right eyes. We investigated the relationship between ONCBA and ipsilateral BCVA. Large ONCBA was clearly related to unfavorable ipsilateral visual acuity (Table 2). ONCBA was correlated with $\log$ MAR visual acuity (Fig. 4). Ipsilateral BCVA improved after surgery on the side with large ONCBA (Fig. 5). All these findings indicated that large ONCBA due to sellar and suprasellar lesions may be related to the ipsilateral visual acuity impairment (Fig. 6).

Many sellar and parasellar lesions develop from the pituitary gland and pituitary stalks, and show approximately upward progression from the midline skull base. Therefore, coronal and sagittal MR images have been commonly used for the diagnosis of sellar and suprasellar lesions. ${ }^{15,29}$ The standard imaging protocol of this part of the tumor still consists of coronal and sagittal T1-weighted MRI with or without gadolinium enhancement. ${ }^{3,40}$ Coronal T2-weighted imaging has been used to add qualitative assessment of lesions. However, sagittal T2-weighted imaging is not often used as the basic protocol because of the long imaging time. ${ }^{3,40}$ Generally, T2-weighted imaging is superior to T1-weighted imaging for the detection of cranial nerves in the subarachnoid space. Consequently, sagittal ONCBA has never been investigated until now.

Upward displacement of the intracranial part of the optic apparatus by the suprasellar tumor results in 3D bending of the optic nerve at the entrance to the optic canal from the intracranial subarachnoid space. Such bending will involve compression against the edge of the bony margin of the optic canal and local nerve stretching. Optic nerve compression leads to decreased conduction and to demyelination. The process of demyelination after nerve compression has been observed even after 2 days in animal experimental studies., ${ }^{4,5}$ Remyelination can be observed after several weeks under continuous nerve compression, although remyelinated fibers do not appear to attain the normal thickness and organizational structure, and coexist with completely demyelinated fibers. ${ }^{4,5,9,39}$ Such demyelination with partial chronic remyelination after regional optic nerve compression results in slowly progressive visual dysfunction. Local compression in the narrow peripheral
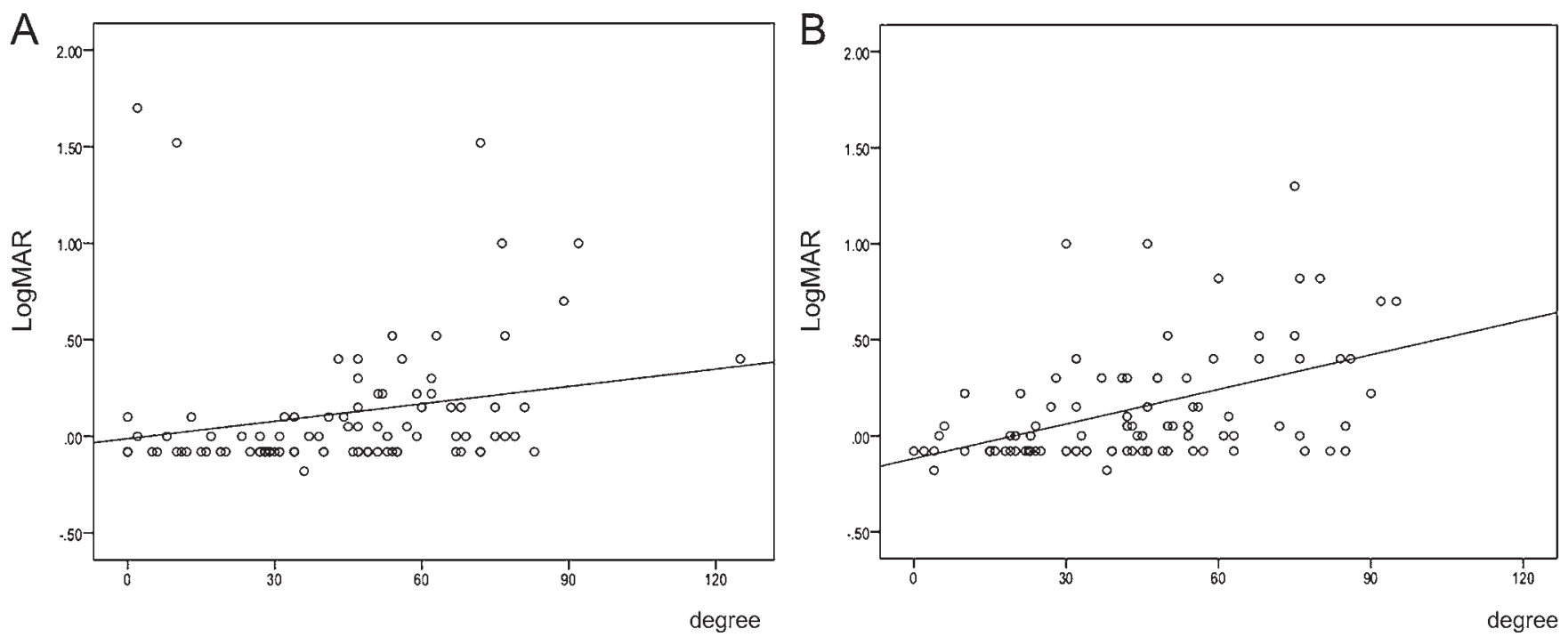

FIG. 4. Graphs showing the correlation between the ONCBA and visual acuity using logMAR vision on the right (A) and left (B) side. The ONCBA had a positive correlation with ipsilateral BCVA (A, right: $r=0.297, p=0.031 ; B$, left: $r=0.451, p=0.000$ ). 
Yamaguchi et al.
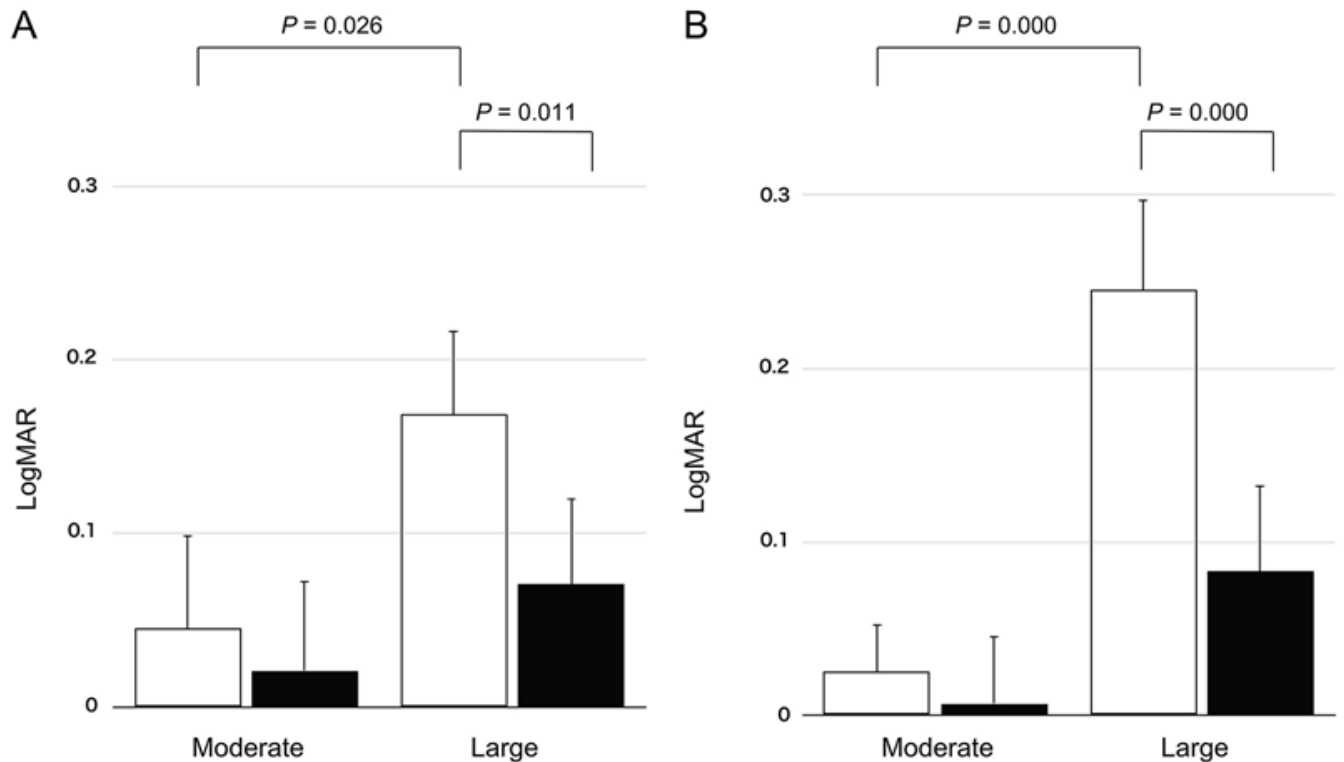

FIG. 5. Difference between pre- (white bar) and postoperative (black bar) visual acuity on the right (A) and left (B) sides. The preoperative BCVA was significantly lower on the same side in the large ONCBA group than in the moderate group (right side: large ONCBA group $0.169 \pm 0.333$ vs moderate ONCBA group $0.045 \pm 0.359, n=49$ vs $44, p=0.026$, Student t-test; left side: large ONCBA group $0.245 \pm 0.346$ vs moderate ONCBA group $0.025 \pm 0.333, n=44$ vs $49, p=0.000$ ). In the case of large ONCBA, visual acuity (logMAR) was improved after resection of the tumor with significant differences on both sides (right side: before $0.169 \pm 0.333$ vs after $0.071 \pm 0.341, n=49, p=0.011$, Student t-test; left side: before $0.245 \pm 0.346$ vs after $0.083 \pm 0.329, n=44, p=0.000$ ). In the case of moderate ONCBA, preoperative visual acuity was not impaired, with almost no change after resection of the tumor.

optic nerve may be more likely to cause functional disturbance of the whole optic nerve cord than local compression in the relatively strong and large chiasm.

On the other hand, regional optic nerve compression and stretching may be associated with regional nerve ischemia. The optic chiasm is supplied by branches from the internal carotid, anterior cerebral, and anterior communicating arteries. ${ }^{7}$ The distal intracranial and intracanalicular parts of the optic nerve are mainly supplied by the superior hypophyseal arteries. The contribution of the ophthalmic artery to this part of the nerve is negligible. ${ }^{43}$ The distal intracranial to intracanalicular part of the optic nerve receives poorer arterial and arteriolar blood supply than the other parts of the optic nerve..$^{12,16,43}$ This part may be prone to ischemic optic nerve neuropathy. ${ }^{31}$ The blood supplies from the arteries and arterioles in the optic nerve decrease in the order of chiasm, intracranial optic nerve, and intracanalicular optic nerve. ${ }^{12}$ The optic nerve has poor blood flow at the exit of the optic canal, and local microscopic blood flow disturbance may be likely due to strong bending and compression by the edge of the optic canal bony margin and local nerve stretching. Consequently, regional ischemia may also be involved in visual disturbance.

The postoperative improvement in visual acuity does not parallel changes in the visual field in every case. ${ }^{35}$ Visual acuity improves in the first months after surgical treatment ${ }^{6,42}$ and visual field defects continue to improve for at least 1 year. Recovery of visual acuity may be fast, whereas recovery of the visual field occurs later. ${ }^{21}$ Postoperative visual acuity was greatly improved in the large ONCBA side within 3 months after surgery (Fig. 5). Such early recovery is probably due to restoration of the velocity
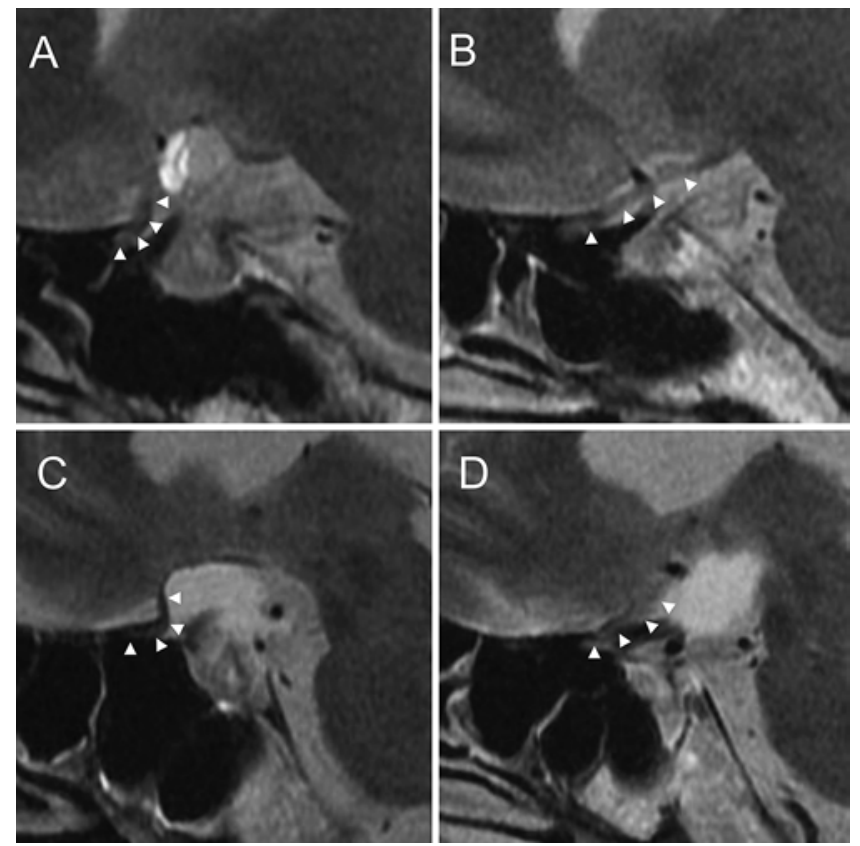

FIG. 6. Case presentations demonstrating optic nerve trajectory (arrowheads) on sagittal T2-weighted MR images. A and B: Case 1, a 44-yearold woman with pituitary adenoma. A large ONCBA was indicated on the right side $(A)$ and moderate ONCBA on the other side $(B)$. Preoperative BCVA (logMAR) was 0.52 on the right side and -0.08 on the left side. Her right-side visual acuity improved to -0.08 after removal of the tumor. C and D: Case 2, a 61-year-old man with craniopharyngioma. A large ONCBA was indicated on the right side $(C)$ and moderate ONCBA on the other side (D). Preoperative BCVA (logMAR) was 1.00 on the right side and -0.08 on the left side. His right-side visual acuity improved to -0.08 after removal of the tumor. 
of conduction. In addition, local ischemia by bending of the optic nerve at the exit of the optic canal may contribute to ipsilateral visual acuity impairment. The recovery of the optic nerve local ischemia may improve ipsilateral visual acuity after removal of the tumor.

Craniopharyngioma is a highly variable tumor presenting with large or small cysts, calcification, and irregular shape. Visual symptoms are known to be often nonspecific and variable., ${ }^{2,14}$ Irregularly shaped pituitary adenoma sometimes presents with irregular visual field defect and severe decrease in visual acuity. ${ }^{30}$ These disorders may be partially caused by bending of the optic nerve at the entrance to the optic canal from the intracranial subarachnoid space. Consequently, the importance of the ONCBA must be examined in various diseases, tumors, and lesion conformations.

The present study did not consider the temporal course related to compression of the visual pathway. Compression speed of the visual path may vary, depending on the tumor growth rate. Vision dysfunction could also be affected by this growth rate. However, the rate of change is difficult to accurately predict for individual cases. This study did not consider this issue. This study also did not investigate the long-term prognosis of visual acuity after surgery. However, the severity of preoperative ONCBA and the length of the compression period may be related to the long-term visual prognosis. Further study is needed in the future. The optic nerve angle at the exit of the optic canal was measured in the sagittal direction for 3D optic nerve bending. This angle is not completely representative of the 3D bending at the contact point between the free subarachnoid space and the optic canal. The 3D structure of the optic pathway and visual functions are subjects for investigation in the future.

\section{Conclusions}

Preoperative MRI findings of sagittal bending of the optic nerve at the entrance to the intracranial subarachnoid space from the optic canal might be involved in the decrease of ipsilateral visual acuity. Investigation of visual function problems caused by sellar and parasellar lesions needs to consider the combination of chiasmatic compression and this new concept.

\section{Acknowledgments}

This study was partly supported by grants from the Japan Society for the Promotion of Science.

\section{References}

1. Barzaghi LR, Medone M, Losa M, Bianchi S, Giovanelli M, Mortini P: Prognostic factors of visual field improvement after trans-sphenoidal approach for pituitary macroadenomas: review of the literature and analysis by quantitative method. Neurosurg Rev 35:369-379, 2012

2. Chen C, Okera S, Davies PE, Selva D, Crompton JL: Craniopharyngioma: a review of long-term visual outcome. Clin Exp Ophthalmol 31:220-228, 2003

3. Cho CH, Barkhoudarian G, Hsu L, Bi WL, Zamani AA, Laws ER: Magnetic resonance imaging validation of pituitary gland compression and distortion by typical sellar pathology. J Neurosurg 119:1461-1466, 2013
4. Clifford-Jones RE, Landon DN, McDonald WI: Remyelination during optic nerve compression. J Neurol Sci 46:239243, 1980

5. Clifford-Jones RE, McDonald WI, Landon DN: Chronic optic nerve compression. An experimental study. Brain 108:241-262, 1985

6. Cohen AR, Cooper PR, Kupersmith MJ, Flamm ES, Ransohoff J: Visual recovery after transsphenoidal removal of pituitary adenomas. Neurosurgery 17:446-452, 1985

7. Collette JM, Francois J, Neetens A: Vascularization of the optic pathway. V. Chiasma. Br J Ophthalmol 40:730-741, 1956

8. Cushing H, Walker CB: Distortions of the visual fields in cases of brain tumours: chiasmal lesions, with especial reference to bitemporal hemianopsia. Brain 37:341-400, 1915

9. Dekkers OM, de Keizer RJ, Roelfsema F, vd Klaauw AA, Honkoop PJ, van Dulken H, et al: Progressive improvement of impaired visual acuity during the first year after transsphenoidal surgery for non-functioning pituitary macroadenoma. Pituitary 10:61-65, 2007

10. el-Mahdy W, Powell M: Transsphenoidal management of 28 symptomatic Rathke's cleft cysts, with special reference to visual and hormonal recovery. Neurosurgery 42:7-17, 1998

11. Fahlbusch R, Schott W: Pterional surgery of meningiomas of the tuberculum sellae and planum sphenoidale: surgical results with special consideration of ophthalmological and endocrinological outcomes. J Neurosurg 96:235-243, 2002

12. Francois J, Neetens A, Collette JM: Vascularization of the primary optic pathways. Br J Ophthalmol 42:65-80, 1958

13. Gan L, Ma J, Feng F, Wang Y, Cui J, Guo X, et al: The predictive value of suprasellar extension for visual function evaluation in Chinese patients with nonfunctioning pituitary adenoma with optic chiasm compression. World Neurosurg 116:e960-e967, 2018

14. Garnett MR, Puget S, Grill J, Sainte-Rose C: Craniopharyngioma. Orphanet J Rare Dis 2:18, 2007

15. Hawkes RC, Holland GN, Moore WS, Corston R, Kean DM, Worthington BS: The application of NMR imaging to the evaluation of pituitary and juxtasellar tumors. AJNR Am J Neuroradiol 4:221-222, 1983

16. Hayreh SS: Orbital vascular anatomy. Eye (Lond) 20:11301144, 2006

17. Ikeda H, Yoshimoto T: Visual disturbances in patients with pituitary adenoma. Acta Neurol Scand 92:157-160, 1995

18. Imhan KI, Baharudin BTHT, Sakaria A, Smail MISB, Alsabti NMH, Ahmad AK: Improve the material absorption of light and enhance the laser tube bending process utilizing laser softening heat treatment. Opt Laser Technol 99:15-18, 2018

19. Jacobsen MF, Thomsen ASS, Bach-Holm D, Doroudian G, Nissen KR, Fugleholm K, et al: Predictors of visual outcome in patients operated for craniopharyngioma - a Danish national study. Acta Ophthalmol 96:39-45, 2018

20. Jaeger W, Thomann H: [German Ophthalmological Association. Recommendations for evaluation of reduced earning capacity caused by damage to vision. September 1981.] Klin Monatsbl Augenheilkd 180:242-244, 1982 (German)

21. Kerrison JB, Lynn MJ, Baer CA, Newman SA, Biousse V, Newman NJ: Stages of improvement in visual fields after pituitary tumor resection. Am J Ophthalmol 130:813-820, 2000

22. Kitano M, Taneda M, Nakao Y: Postoperative improvement in visual function in patients with tuberculum sellae meningiomas: results of the extended transsphenoidal and transcranial approaches. J Neurosurg 107:337-346, 2007

23. Laws ER Jr, Trautmann JC, Hollenhorst RW Jr: Transsphenoidal decompression of the optic nerve and chiasm. Visual results in 62 patients. J Neurosurg 46:717-722, 1977

24. Lee IH, Miller NR, Zan E, Tavares F, Blitz AM, Sung H, et 
al: Visual defects in patients with pituitary adenomas: the myth of bitemporal hemianopsia. AJR Am J Roentgenol 205:W512-W518, 2015

25. Levy A: Pituitary disease: presentation, diagnosis, and management. J Neurol Neurosurg Psychiatry 75 (Suppl 3):iii47-iii52, 2004

26. Liugan M, Xu Z, Zhang M: Reduced free communication of the subarachnoid space within the optic canal in the human. Am J Ophthalmol 179:25-31, 2017

27. Long H, Qi ST, Song Y, Pan J, Zhang XA, Yang KJ: Topographic variations of the optic chiasm and the pituitary stalk: a morphometric study based on midsagittal T2-weighted MR images. Surg Radiol Anat 36:775-781, 2014

28. Luomaranta T, Raappana A, Saarela V, Liinamaa MJ: Factors affecting the visual outcome of pituitary adenoma patients treated with endoscopic transsphenoidal surgery. World Neurosurg 105:422-431, 2017

29. Maravilla KR, Kirks DR, Maravilla AM, Diehl JT: Computed tomography in the evaluation of sella and parasella lesions: the value of sagittal and coronal reconstructions. Comput Tomogr 2:237-249, 1978

30. Matsuyama J, Kawase T, Yoshida K, Hasegawa M, Hirose Y, Nagahisa S, et al: Management of large and giant pituitary adenomas with suprasellar extensions. Asian J Neurosurg 5:48-53, 2010

31. Mendel E, Stoicea N, Rao R, Niermeyer W, Revilla S, Cluse $\mathrm{M}$, et al: Revisiting postoperative vision loss following nonocular surgery: a short review of etiology and legal considerations. Front Surg 4:34, 2017

32. Müslüman AM, Cansever T, Yılmaz A, Kanat A, Oba E, Çavuşoğlu H, et al: Surgical results of large and giant pituitary adenomas with special consideration of ophthalmologic outcomes. World Neurosurg 76:141-148, 63-66, 2011

33. Ogra S, Nichols AD, Stylli S, Kaye AH, Savino PJ, DaneshMeyer HV: Visual acuity and pattern of visual field loss at presentation in pituitary adenoma. J Clin Neurosci 21:735740, 2014

34. Poon A, McNeill P, Harper A, O’Day J: Patterns of visual loss associated with pituitary macroadenomas. Aust N Z J Ophthalmol 23:107-115, 1995

35. Powell M: Recovery of vision following transsphenoidal surgery for pituitary adenomas. Br J Neurosurg 9:367-373, 1995

36. Prieto R, Pascual JM, Barrios L: Optic chiasm distortions caused by craniopharyngiomas: clinical and magnetic resonance imaging correlation and influence on visual outcome. World Neurosurg 83:500-529, 2015

37. Rao GP, Blyth CP, Jeffreys RV: Ophthalmic manifestations of Rathke's cleft cysts. Am J Ophthalmol 119:86-91, 1995
38. Schmalisch K, Milian M, Schimitzek T, Lagrèze WA, Honegger J: Predictors for visual dysfunction in nonfunctioning pituitary adenomas - implications for neurosurgical management. Clin Endocrinol (Oxf) 77:728-734, 2012

39. Smith KJ, Blakemore WF, McDonald WI: The restoration of conduction by central remyelination. Brain 104:383-404, 1981

40. Soto-Ares G, Cortet-Rudelli C, Assaker R, Boulinguez A, Dubest C, Dewailly D, et al: MRI protocol technique in the optimal therapeutic strategy of non-functioning pituitary adenomas. Eur J Endocrinol 146:179-186, 2002

41. Tosaka M, Sato N, Hirato J, Fujimaki H, Yamaguchi R, Kohga $\mathrm{H}$, et al: Assessment of hemorrhage in pituitary macroadenoma by T2*-weighted gradient-echo MR imaging. AJNR Am J Neuroradiol 28:2023-2029, 2007

42. Trautmann JC, Laws ER Jr: Visual status after transsphenoidal surgery at the Mayo Clinic, 1971-1982. Am J Ophthalmol 96:200-208, 1983

43. van Overbeeke J, Sekhar L: Microanatomy of the blood supply to the optic nerve. Orbit 22:81-88, 2003

44. Wang H, Sun W, Fu Z, Si Z, Zhu Y, Zhai G, et al: The pattern of visual impairment in patients with pituitary adenoma. J Int Med Res 36:1064-1069, 2008

\section{Disclosures}

The authors report no conflict of interest concerning the materials or methods used in this study or the findings specified in this paper.

\section{Author Contributions}

Conception and design: Tosaka, Yamaguchi. Acquisition of data: Yamaguchi, Miyagishima, Osawa, Horiguchi, Honda. Analysis and interpretation of data: Tosaka, Yamaguchi, Miyagishima, Osawa. Drafting the article: Tosaka, Yamaguchi. Critically revising the article: Tosaka, Osawa, Horiguchi, Honda, Yoshimoto. Reviewed submitted version of manuscript: Tosaka, Miyagishima, Osawa, Horiguchi, Honda, Yoshimoto. Approved the final version of the manuscript on behalf of all authors: Tosaka. Statistical analysis: Yamaguchi. Administrative/technical/ material support: Tosaka, Miyagishima, Horiguchi, Honda. Study supervision: Yoshimoto.

\section{Correspondence}

Masahiko Tosaka: Gunma University Graduate School of Medicine, Gunma, Japan.nstosaka@gunma-u.ac.jp. 